\title{
Group Size and Group Composition of the Mona Monkey (Cercopithecus mona) on the Island of Grenada, West Indies
}

\author{
MARY E. GLENN" \\ Windward Islands Research and Education Foundation, Barshore. New York
}

Cercopithecus, the genus of guenons, is the largest of the African primate genera, and yet more than half of the species belonging to this group have never been the focus of a long-term field study. In this paper, I present data on group size and composition for a previously unstudied population of guenons on the Caribbean island of Grenada. The mona monkey, Cercopithecus mona, was introduced to Grenada from Africa approximately 200-300 years ago. Two types of social groups were found for Cercopithecus mona on Grenada: all-male groups consisting of two to four individuals and bisexual groups containing 5-32 individuals. Allmale groups of Grenada mona monkeys contained any combination of juveniles, subadults, and/or adults. All-male groups were a common occurrence on Grenada but have never been reported for African C. mona and have been reported only in two other forest Cercopithecus species. Bisexual groups appeared to consist of one adult male, one to six adult females, subadult females, and juveniles and infants of both sexes. Even though no more than one adult male was ever seen in each bisexual group of monas on Grenada, other males were heard giving copulation calls simultaneously with resident adult male loud calls, suggesting that other males occasionally infiltrate bisexual groups. Am. J. Primatol. 43:167-173, 1997.

\section{Key words: Cercopithecus mona; Eastern Caribbean; guenon; social structure}

\section{INTRODUCTION}

Even though the Cercopithecus genus is the largest and most varied of all the African primate genera [Maranto, 1986; Ruvolo, 1988], guenons as a group are understudied. Because most Cercopithecus monkeys live in dense forest habitat and are hunted over most of their range, less than half of the members of this genus have been the subject of a long-term field study [Cords, 1987]. Like many forest guenons, little is known about the African mona monkey (Cercopithecus mona). Previous to this study, nothing was known about a population of mona monkeys which was introduced to the Caribbean island of Grenada approximately 200-300 years ago.

Correspondence to: Mary E. Glenn, Windward Islands Research and Education Foundation, 11 East Main Street, Suite 154, Bayshore, NY 11706.

Received for publication 7 November 1996; revision accepted 5 May 1997

(C) 1997 Wiley-Liss, Inc. 


\section{8 / Glenn}

Few data are available concerning the social structure of $C$. mona in Africa. Only three studies provided information regarding mona group size and composition [Howard, 1977; Struhsaker, 1969; Whitesides, 1981]. Group size estimates for $C$. mona have also been reported from five other studies, but many of these were based on cursory observations [Monath \& Kemp, 1973; Dunn, 1993; Feiler et al., 1993; Gartlan, 1973; Happold, 1987J. In this paper, information on group size and composition for the introduced population of C. mona on Grenada is presented.

\section{METHODS \\ Study Site}

This study was conducted over 28 months between September 1992 and April 1995 in the mountainous rain forests of the 1,540 ha Grand Etang National Park and Forest Reserve $\left(12^{\circ} 6\right.$ N , 61 $42^{\circ} \mathrm{S}$ ) (Fig. 1). To facilitate daily trail surveys, 22 $\mathrm{km}$ of trails were cut and marked at $100 \mathrm{~m}$ intervals throughout the study site. Cercopithecus mona is the only nonhuman primate found on Grenada and has no predators aside from human hunters. Hunting pressure on the monkeys is considerable because no guards are employed to monitor the park and forest reserve [Bensen and Glenn, in preparation].

\section{Data Collection}

Groups were defined as aggregations of two or more monkeys whose affiliative interactions, such as grooming, playing, and contact calling, were confined to one another. Individual monkeys were also considered part of a group if they were traveling along the same route of progression or observed within $50 \mathrm{~m}$ of other monkeys.

Age class estimates of group members were based on knowledge of captive monkeys' ages and development. The following definitions were used: adult (males, $\geq 5$ years; females, $\geq 4$ years), subadult (males, 3-4 years; females, 2-3 years), juvenile ( $1-3$ years), infant ( $0-1$ year). Adult females were identified by the presence of pendulant nipples |Struhsaker, 1969|. Adult males were distinguished from subadult and juvenile males by their larger blue scrotum, comparatively larger size, and deeper vocalizations. Determining the sex of younger individuals was difficult unless the observer was directly underneath the monkey. It was impossible to determine the sex of small juveniles and infants.

Group size and composition were determined using two methods: 1) "habituated" monkeys were identified, counted, and observed every time they visited the field station (a small house immediately surrounded by forest and located one-quarter mile from the park visitor center) (Fig. 1), and 2) individuals in "unhibituated" monkey groups were counted whenever possible during daily trail surveys.

Habituated monkeys were fed by tourists at the park visitor center and had become accustomed to humans. These monkeys began to frequent the field station immediately after the study started and were occasionally provisioned with fruit by the field researchers.

Unhabituated monkeys were never provisioned by humans and did not frequent the field station or park visitor center. Efforts were made to systematically follow unhabituated monkey groups; however, most observations of these monkeys were opportunistic because of their shyness due to hunting. As a consequence, group size estimates for unhabituated monkeys were often based on the number of areas of movement seen and the number of different vocalizations 
Social Structure of Cercopithecus mona / 169

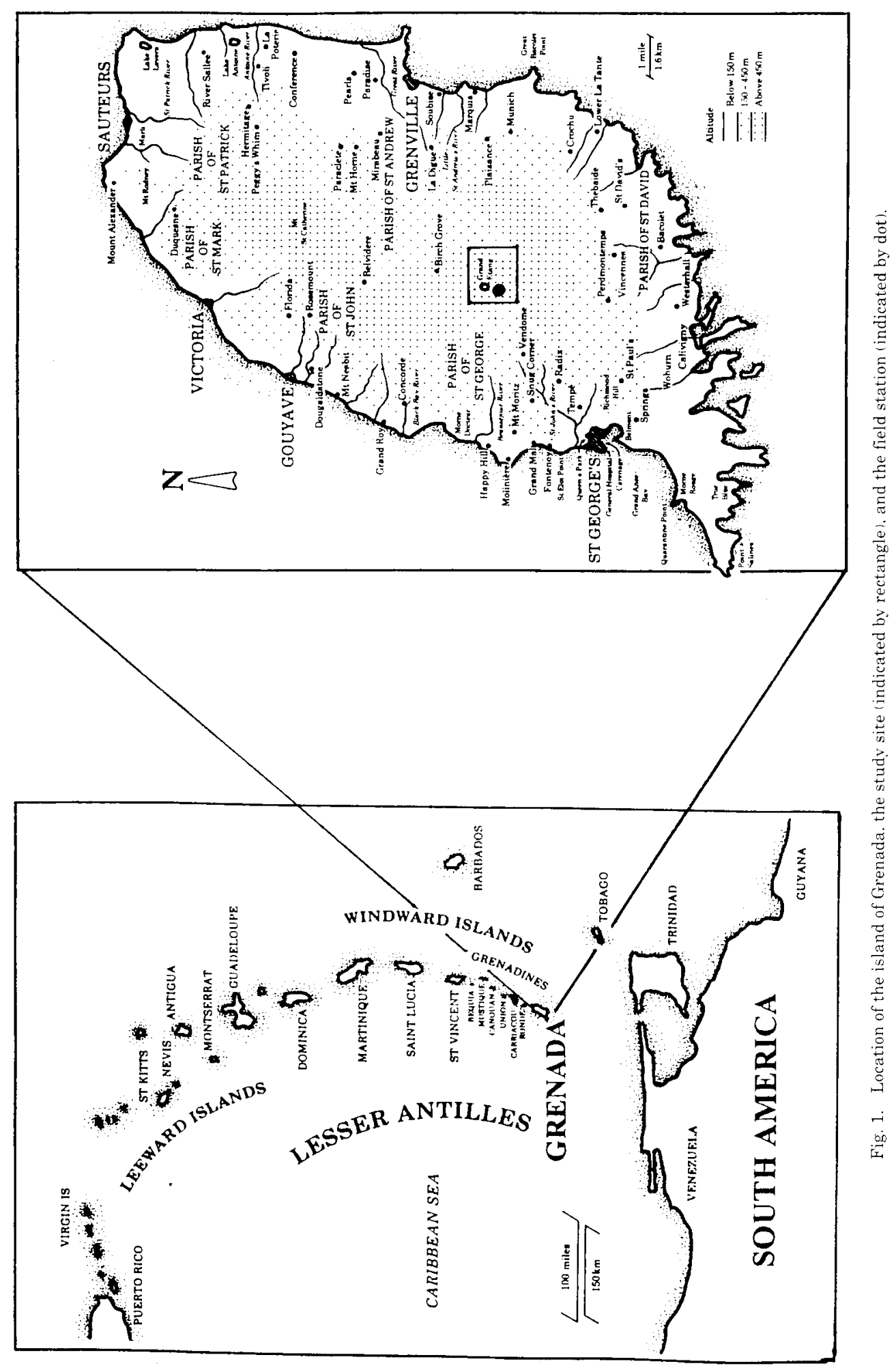


heard. However, reliable counts and descriptions of group composition of unhabituated monkey groups were obtained when the duration of a sighting was considerable or when the monkeys were traveling along the same route in progression in clear view. These counts and group descriptions were confirmed by repeated sightings of the same groups (i.e., groups encountered at the same location many times and containing one or two identifiable members).

\section{RESULTS \\ Habituated Monkey Groups}

Habituated monkey groups were sighted 1,164 times. All monkeys within these groups were males and were individually identifiable. Each of the different male groups that formed over the 28 month field study was seen almost daily when they were together, and all groups allowed field researchers to follow them back into the forest to observe them. Habituated monkeys were never observed in a bisexual group at any time during their tenure in an all-male group.

Eighteen different individuals (eight adult, eight subadult, and two juvenile monkeys) belonged at some time to one or more of 33 different all-male groups. Habituated all-male groups contained from two to four individuals $(\overline{\mathrm{x}}=2.4, \mathrm{SD}=$ 0.6 ). Several male pairs formed long-term, stable associations; one pair was seen consistently together for more than 2 years, and three other pairs contained the same members for 1 year or more. The mean number of months male pairs were observed together was 7.7 ( $\mathrm{SD}=7.1, \min =1, \max =25, \mathrm{n}=12$ ). This average was lower for male trios $(\overline{\mathrm{x}}=2.4$ months, $\mathrm{SD}=1.1, \min =0.5, \max =5, \mathrm{n}=18$ ) and foursomes $(\overline{\mathrm{x}}=2.5$ months, $\mathrm{SD}=1.3, \min =1.5, \max =4, \mathrm{n}=3$ ).

Thirteen combinations of age classes were recorded within the 33 groups, of which the most frequently seen were subadult/subadult pairs $(\mathrm{n}=5)$ and adult/ subadult pairs $(n=4)$. Solitary juvenile, subadult, and adult male monkeys were also observed ( $\mathrm{n}=9$ ); however, most of these males had also belonged to an allmale association at some point in time.

\section{Unhabituated Monkey Groups}

Unhabituated monkeys were encountered 308 times during daily trail surveys. Twenty-six of these sightings were confirmed all-male groups consisting of either two or three individuals $(\overline{\mathrm{x}}=2.2, \mathrm{SD}=0.4)$. Of these, groups of two males were most commonly observed $(77 \%)$. Five combinations of age classes were recorded within the 26 all-male group sightings; the most frequently seen were pairs of subadult males $(n=8)$. Members of both habituated and unhabituated all-male associations interacted often and were frequently observed grooming, playing, and resting together. Solitary subadult and adult male monkeys were observed in the wild on eight occasions. Bisexual groups were encountered 206 times. The number of individuals in bisexual groups ranged between five and $32(\overline{\mathrm{x}}=18.0$, $\mathrm{SD}=7.0$ ). The remaining 68 sightings consisted of incomplete group size estimates or group composition descriptions and were not included in these analyses.

Data regarding the composition of bisexual groups are few because groups were never fully habituated and rarely were group members individually identifiable. The mean duration of sightings of unhabituated monkey groups was only $17.1 \min (\mathrm{SD}=28.8, \min =1, \max =310$ ). Therefore, data concerning bisexual group composition were based upon 1) 29 sightings where all adult monkeys were clearly identified and the sex and age of several younger monkeys determined and 2) inferences made from the pitch and type of vocalizations given by 
different members within a group during sightings when all group members were not clearly visible.

Group size and composition were confirmed for four groups in the study area by obtaining repeated counts of these groups (mean number of clear sightings per group $=7.3, \mathrm{SD}=2.6, \min 5, \max =11, \mathrm{n}=29$ ). More than one adult male never was seen in each of these groups. In addition, only one individual per bisexual group was ever heard giving loud calls characteristic of adult males [Glenn, 1996]. However, during $26 \%$ of all copulation calls heard $(n=104)$, adult male loud calls from within the same bisexual group were heard simultaneously. In $37 \%$ of these cases, the adult male giving the loud calls was in view while copulation calls were given at very close range, indicating that more than one adult male per group was present. The number of adult females in bisexual groups ranged from one to six $(\bar{x}=3.1, \mathrm{SD}=1.4)$, and the remaining members of these groups were made up of immature males and females.

\section{DISCUSSION}

\section{Solitary Males and All-Male Groups}

In Africa, the occurrence of solitary male mona monkeys is common |Howard, 1977; Struhsaker, 1969|. Solitary males have also been documented in two other members of the mona superspecies [C. pogonias pogonias: Struhsaker, 1969; $C$. wolfi denti: Kingdon, 1971| and in a number of other Cercopithecus species $\mid C$. mitis stuhlmanni: Haddow, 1952; Rudran, 1978; Butynski, 1990; C. ascanius schmidti: Haddow, 1952; Struhsaker, 1988; C. nictitans martini and C. erythrotis: Struhsaker, 1969|.

In contrast, the occurrence of all-male groups appears to be a rare phenomenon in African forest guenons. All-male groups have not been reported for any populations of African C. mona. In other African forest Ceropithecus species, allmale associations have been documented only in two populations $\mid C$. campbelli lowei: Bourlière et al., 1970; C. mitis stuhlmanni: Tsingala and Rowell 1984l.

Additional research of unstudied guenon populations is needed in order to determine if the presence of all-male groups is indeed a rare phenomenon within the Cercopithecus genus and, if so, why.

\section{Bisexual Groups}

The mean size and range of bisexual groups of monas on Grenada fit within those reported for African mona monkeys. Struhsaker [1969|, Howard |1977|, and Whitesides |1981| documented mean mona group sizes of 8.8 (range 3-13, n $=6$ ), 19 (range $6-35, \mathrm{n}=4$ ), and 20 (range $12-35, \mathrm{n}=13$ ), respectively. Other researchers have reported group size ranges for $C$. mona between five and 38 |Dunn, 1993; Feiler et al., 1993; Gartlan, 1973; Happold, 1987; Monath \& Kemp, 1973|.

The composition of mona bisexual groups on Grenada also appears similar to that described for most African forest guenons, including African C. mona. My data are inconclusive but suggest that C. mona bisexual groups on Grenada generally contain one adult male but periodically experience influxes of other sexually mature males. Similarly, bisexual groups of African C. mona have been described both as containing one adult male [Howard, 1977; Struhsaker, 1969; Whitesides, 1981] and several adult males [Gartlan, 1973; Howard, 1977]. Moreover, both one-male bisexual groups as well as bisexual groups periodically containing more than one sexually mature male have been documented for most other forest guenon species [see Cords, 1987, 1988; Struhsaker, 1969, 1988]. 


\section{2 / Glenn}

The habitat in Grenada varies from the mona's habitat in African, and yet the bisexual group size and composition seen in Grenada C. mona appear to mirror those of African monas, suggesting that this may be a species-typical characteristic. However, more data are needed from C. mona on Grenada in order to confirm whether its bisexual group structure is truly a reflection of that observed in African monas, as well as in other African forest guenons, before further conclusions may be made.

\section{CONCLUSIONS}

1. Two types of social groups were found for Cercopithecus mona on Grenada: all-male groups consisting of two to four individuals and bisexual groups, containing five to 32 individuals.

2. All-male groups of Grenada mona monkeys may contain any combination of juveniles, subadults and/or adults, while bisexual groups appear to consist of one adult male, one to six adult females, subadult females, and juveniles and infants of both sexes.

3. All-male groups were a common occurrence in Grenada $C$. mona but have never been reported for African C. mona, and have been reported only in two other forest Cercopithecus species.

4. Even though no more than one adult male was ever seen in each bisexual group of monas on Grenada, other males were heard giving copulation calls simultaneously with resident adult male loud calls, suggesting that other males infiltrate bisexual groups at some points in time.

\section{ACKNOWLEDGMENTS}

My research on Grenada would have been impossible without the permission generously granted to me by the Honorable Mr. Tillman Thomas and Ms. Lana McPhail of the Ministries of Tourism and Labour of the Government of Grenada, Mr. Michael Phillip and Mr. Raymond Walker of the Grenada National Parks and Protected Areas, and Mr. Allan Joseph of the Grenada Forestry Department, all to whom I am grateful. Special thanks must be given to Mr. Keith Bensen, Ms. Heather Bruce, and Mr. Oscar "Chest" Andall for their tireless efforts in searching for elusive monkeys and assistance in the field. I am indebted to Drs. Malcolm Dow, Marian Dagosto, and Brian Shea for their advice and generous help given throughout all stages of this research. I also thank Mr. Keith Bensen and five anonymous reviewers for their helpful criticism during the preparation of this manuscript. Funding for this work was provided by the Windward Islands Research and Education Foundation, The Rockefeller University, the Yerkes Regional Primate Research Center, the Foundation for Field Research, Sigma XiThe Scientific Research Society, and the Research Grants Committee of Northwestern University.

\section{REFERENCES}

Bensen, K.J.; Glenn, M.E. Population size, hunting rates, and sustainability of mona monkeys (Cercopithecus mona) on the Caribbean island of Grenada, in preparation.

Bourlière, F.; Hunkeler, C.; Bertrand, M Ecology and behavior of Lowe's guenon (Cercopithecus campbelli lowei) in the
Ivory Coast. Pp. 297-350 in OLD WORLD MONKEYS: EVOLUTION, SYSTEMATICS AND BEHAVIOUR. J.R. Napier; P.H. Napier, eds. New York, Academic Press, 1970.

Butynski, T.M. Comparative ecology of blue monkeys (Cercopithecus mitis) in high- 


\section{Social Structure of Cercopithecus mona / 173}

and low-density subpopulations. ECOLOGICAL MONOGRAPHS 60(1):1-26, 1990.

Cords, M. Forest guenons and patas monkeys: Male-male competition in one-male groups. Pp. 98-111 in PRIMATE SOCIETIES. B.B. Smuts; D.L. Cheney; R.M. Seyfarth; R.W. Wrangham; T.T. Struhsaker, eds. Chicago, University of Chicago Press, 1987.

Cords, M. Mating systems of forest guenons: A preliminary review. Pp. 323-339 in A PRIMATE RADIATION: EVOLUTIONARY BIOLOGY OF THE AFRICAN GUENONS. A. Gautier-Hion; F. Bourlière; J.-P. Gautier; J. Kingdon, eds. Cambridge, England, University Press, 1988.

Dunn, A. THE LARGE MAMMALS OF GASHAKA GUMPTI NATIONAL PARK, NIGERIA. A report prepared for the Federal Ministry of Agriculture, Water Resources and Rural Development of Nigeria Nigerian Conservation Foundation, and World Wildlife Fund for Nature, Godalmig, Surrey, United Kingdom, 1993.

Feiler, A.; Haft, J.; Widmann, P. Beobachtungen und untersuchungen an säugetieren der insel Sāo Tomé (Golf von Guinea). FAUNISTISCHE ABHANIDLUNGEN 19(4): 21-35, 1993.

Gartlan, J.S. Influences of phylogeny and ecology on variations in the group organization of primates. Pp. 88-101 in PRECULTURAI PRIMATE BEHAVIOR, SYMPOSIUM OF THE IV'TH INTERNATIONAI _ CONGRESS OF PRIMA'TOLOGY, VOL. 1. E.W. Menzel, ed. Basel, Karger, 1973.

Glenn, M.E. THE NATURAL, HISTORY AND ECOLOGY OF THE MONA MONKEY (CERCOPITHECUS MONA SCHREBER 1774) ON THE ISLAND OF GRENADA WEST INDIES. Ph.D. dissertation, Evanston, IL, Northwestern University, 1996.

Haddow, A.J. Field and laboratory studies on an African monkey, Cercopithecus ascanius schmidti Matschie. PROCEEIINGS OF THE ZOOLOGICAL SOCIETY OF LONDON 122:297-398, 1952.

Happold, D.C.D. THE MAMMALS OF NIGERIA. Oxford, Clarendon Press, 1987.
Howard, R. NICHE SEPARATION AMONG THREE SYMPATRIC SPECIES OF CERCOPITHECUS MONKEYS. Ph.D. dissertation, Austin, TX, The University of Texas, 1977.

Kingdon, J. EAST AFRICAN MAMMALS AN ATLAS OF EVOLUTION IN AFRICA, VOL. 1. London, Academic Press, 1971.

Maranto, G. Will guenons make a monkey of Darwin? DISCOVER (November):87$101,1986$.

Monath, T.P.; Kemp, G.E. Importance of nonhuman primates in yellow fever epidemiology in Nigeria. TROPICAL AND GEOGRAPHICAL MEDICINE 25:28-38, 1973.

Rudran, R. Socioecology of the blue monkeys (Cercopithecus mitis stuhlmanni) of the Kibale Forest, Uganda. SMITHSONIAN CONTRIBUTIONS TO ZOOLOGY 249:188,1978

Ruvolo, M. Genetic evolution in the African guenons. Pp. 127-139 in A PRIMATE RADIATION: EVOLUTIONARY BIOLOGY OF THE AFRICAN GUENONS. A. Gautier-Hion; F. Bourlière; J.-P. Gautier; J. Kingdon, eds. Cambridge, England, University Press, 1988.

Struhsaker, T.T. Correlates of ecology and social organization among African cercopithecines. FOLIA PRIMATOLOGICA $11: 80-118,1969$

Struhsaker, 'T.T. Male tenure, multi-male influxes, and reproductive success in redtail monkeys (Cercopithecus ascanius). Pp 340363 in A PRIMATE RADIATION EVOLUTIONARY BIOLOGY OF THE AFRICAN GUENONS. A. Gautier-Hion; F. Bourlière; J.-P. Gautier; J. Kingdon, eds. Cambridge, England, University Press, 1988.

Tsingalia, H.M.; Rowell, T.E. The behaviour of adult male blue monkeys. ZEITSCHRIF'T FÜR TIERPSYCHOLOGIE 64:253-268, 1984

Whitesides, G.H. COMMUNI'T'Y AND POPULATION ECOLOGY OF NON-HUMAN PRIMATES IN THE DOUALA-EDEA FOREST RESERVE. M.Sc. thesis, Baltimore, MD, The John Hopkins University, 1981. 